Article

\title{
An Investigation on Responsible Innovation in the Emerging Shared Bicycle Industry: Case Study of a Chinese Firm
}

\author{
Zheng Liu ${ }^{1,2, *}$, Lei Ma ${ }^{2,3, *}$, Yue Zhu ${ }^{2}$ and Wenchao $\mathrm{Ji}^{4}$ \\ 1 Faculty of Business and Society, University of South Wales, Pontypridd CF37 1DL, UK \\ 2 Centre for Innovation and Development, Nanjing University of Science and Technology, \\ Nanjing 210094, China \\ 3 School of Public Affairs, Nanjing University of Science and Technology, Nanjing 210094, China \\ 4 School of Intellectual Property, Nanjing University of Science and Technology, Nanjing 210094, China \\ * Correspondence: zheng.liu@southwales.ac.uk (Z.L.); 12009040@njust.edu.cn (L.M.); \\ Tel.: +44-1443-483-693 (Z.L.); +86-2584-31-5237 (L.M.)
}

Received: 2 June 2019; Accepted: 10 July 2019; Published: 12 July 2019

\begin{abstract}
In the current era of Industrial 4.0, open innovation, and the sharing economy, innovation ecosystems are formed through government-industry-university (triple helix) interaction. The concept of responsible innovation has emerged to explore how innovation can be conducted in a transparent, trustworthy, and sustainable way so as to respond to the public interest. While current literature provides a conceptual framework, details of how responsible innovation can be formed, developed, and sustained in the sharing economy, in particular in developing countries, have been under-explored. This paper aims to explore factors of responsible innovation, linking dimensions with business practice, and identify the dynamic stages of the industry life cycle. Through an in-depth case study of China's shared bicycle industry and the firm Hellobike, this paper has prioritized factors which lead to responsibility, such as user safety and friendliness in product design, real-time operations combined with big data, collaboration between industry and local government for industry standardization, and user credit systems. It has enriched key dimensions based on literature and case studies and proposed dynamic interaction models for industry, government, users, and universities at different stages of responsible innovation in the shared bicycle sector. From this empirical study, future research areas have been identified.
\end{abstract}

Keywords: responsible innovation; triple helix; sharing economy; China

\section{Introduction}

With technology advancement, Internet of things, big data, and government-universityindustry-public collaboration, the sharing economy has become a new phenomenon. Meanwhile, there has been a growth of awareness of current business impacts on the environment and society. The concept of responsible innovation has emerged as a process seeking to create new products, services, and business models in a transparent, trustworthy, and sustainable way, so as to respond to public interest. At the macro level, this can be linked with inclusive innovation studies which consider social development by articulating spatial, seasonal, sectoral, skill, and social factors [1]. This can be further developed as a theory of social inclusive open innovation, connecting industry with societal needs [2]. Recently the proposed conceptual model has also addressed the dynamics of the open innovation economy, closed innovation economy, and social innovation economy, which is known as the open innovation economic system (OIES) theory [3]. As firms seek strategies to combine technology and business growth with social values, the mutual transfer between open/closed innovation and 
social innovation becomes possible [3]. Another stream of theory, triple helix innovation, explores the dynamic interaction between universities, industry, and government [4]. While the literature provides the basis of a conceptual framework, combining business innovation with stakeholders, issues such as how responsible innovation can be formed, developed, and sustained in an emerging sharing economy, in particular with regard to developing country perspectives, have been under-explored.

The sharing economy has developed fast in recent years as a business model with peer-to-peer (P2P)- or business to business (B2B)-based activities involving sharing access to products and services which are facilitated normally by communities based on an online platform. In addition to the sharing business model, resource/supply sharing models, demand sharing models, and technology to support online collaboration and transactions also exist. While lowering industry entry barriers, individuals can get access to underused resources and thus identify a potential new market. Even companies without physical assets can now capture external resources and expand globally with service innovation. Uber and Airbnb are among the successful examples of the sharing economy. With their leading roles, the sharing economy is expected to grow from 14 USD billion in 2014 to 335 USD billion by 2025 [5]. In many European countries, there are shared modes which are highly regulated. However, in China, some representative sharing sectors such as the shared bicycle sector are bottom-up activities. With limited regulation and standardization, there can be risks related to sustainability, responsible development, and improper use of resources. Meanwhile, a trusting relationship between industry and users can be difficult to achieve in the context of the sharing economy, especially in service sectors where focal firms do not own physical assets and business transactions are mainly conducted virtually. As a result, companies need to consider transparent and reliable processes in business model design and operations. Taking Airbnb as an example, without owning properties the company's main competitive advantages are flexibility and low cost when compared with traditional hotel sectors. However, safety and trust can be challenges for both property hosts and guests, the major two types of users, with regard to sharing accommodation with strangers. To minimize the risk, Airbnb considers trust in its business design innovation through risk scoring, background checks, secure payments, a review system, and account protection. With emphasis on responsible innovation and trust, Airbnb has now reached 2 million people staying in homes in 81,000 cities all over the world [6].

China as the world's largest emerging country has witnessed fast growth of the sharing economy since 2014. Statistics show that the scale of China's sharing economy market was around 1956 billion Chinese Yuan Renminbi (RMB) in 2015, with 50 million people participating [7]. In 2018, the transaction volume of China's shared economy market was 2942 billion RMB, showing an annual increase rate of $41.6 \%$. The number of participants was 76 million, including 75 million from service sectors, demonstrating an increase of $7.1 \%$ annually [7]. The sharing economy plays an increasingly prominent role in promoting structural optimization, rapid growth, and transformation of consumption patterns in China's service industries [8]. Within China's sharing economy is the shared bicycle sector, which emerged in 2015 as part of sharing transportation. Through stages of fast growth, it is now facing declining stages with challenges of irresponsibility, disorder, and distrust from both industry and user aspects. The Chinese government has recently launched policies with the aim of supporting responsible and sustainable development of this industry. However, detailed linkages between industry practice and theories of responsible innovation are not yet known.

Driven by theory and practice requirements, this paper aims to explore responsible innovation in the sharing economy from emerging countries. Through case studies of China's shared bicycle industry, it will specifically answer three research questions and hypotheses. (1) Are there any key factors which can lead to responsible and irresponsible innovation? (2) Are there any new meanings and dimensions of responsible innovation in the context of the sharing economy which can enrich the current theory framework? (3) How can industry, government, universities, and society interact dynamically to achieve responsible innovation in a new industry? In particular, does the role of government change at different stages of forming, developing, and sustaining responsible innovation? From this exploratory study, further research themes are proposed for theory testing and enrichment. 


\section{Literature Review}

Research on responsible innovation was originally initiated by the European Commission as an important part of the "Horizon 2020" framework plan which aimed to integrate scientific research resources of EU countries, promoting innovation to meet common challenges [9]. At present, research on responsible innovation mainly focuses on conceptual framework construction. According to Von Schomberg, responsible innovation is "a transparent, interactive process by which societal actors and innovators become mutually responsive to each other with a view to the (ethical) acceptability, sustainability and societal desirability of the innovation process and its marketable products" [10]. Stilgoes et al. has argued that Von Schomberg's definition only reflects European policy and instead a broader view of how responsible innovation can protect the future through collective management should be held [11]. In relation to the U.S.A. context, responsible innovation is regarded as an interactive innovative process related to sustainability and ethical acceptability of development [12]. To explore the construction components of responsible innovation, Stilgoes et al. identified four dimensions, namely, anticipation, reflectiveness, inclusion, and responsiveness [11]. In particular, anticipation involves systematic thinking to increase resilience and reduce risk through public engagement, technology assessment, foresight, horizon scanning, and scenario planning [11]. Reflexivity refers to institutional critiques and self-critiques of activities, commitment, and assumptions, normally by means of codes of conduct, moratoriums, and standardization [11]. Inclusion requires engagement with stakeholders such as the public [11]. Responsiveness evaluates the capacity to change or respond to stakeholder and public values, new knowledges, and other emerging perspectives and views [11]. By studying EU policies, $\mathrm{Li}$ et al. found that the focus of responsible innovation has shifted from risk management to innovation governance, enabling social institutions to make technology innovation more participatory, inclusive, and accountable [13]. Stahl has emphasized the importance of protecting privacy in innovation at both organizational and national levels [14]. Douglas has pointed out that scientists should not only develop professional responsibilities through scientific research but that more importantly they need to highlight potential risks inherent in research to society [15].

The concept of responsible innovation has been introduced to China in recent years, encouraging scholars to redefine and discuss its characteristics within the context of China's society and values. Liu has argued that the innovation community undertakes responsibility for promoting ethics and social wellbeing [16]. However, "full responsibility" or unlimited responsibility is an ideal status, whereas limited responsibility should be conducted in reality [17]. If innovation activities have unlimited responsibility, it will bring challenges of moral overload [17]. In fact, responsible innovation means breaking the excessive restrictions on innovation in ethics, technology, and economy [17]. Mei and Chen have defined responsible innovation as a dynamic process which includes multi-stakeholder collaborative decision-making, forward-looking evaluation of innovation objectives, and results based on existing knowledge [18]. It is an adaptive system of science and technology governance to guide innovation in the direction of meeting social and ethical needs [18]. Based on this, they enrich the framework of Stilgoes et al. [11,18]. Xue and Zhao have emphasized the role of government policy in supporting responsible innovation [19]. From a habitual behavior perspective, Ma has pointed out that organizations should be in charge of responsible innovation and consider the effects of innovation on society to achieve sustainable development [20].

Responsible innovation focuses on the linkage of innovation with society, demonstrating innovation both from scientific and technology advancement and the involvement of stakeholders. The dynamics of responsible innovation can be traced back to the concept of the business ecosystem, which has extended the scope of business from organizations towards a broad range of stakeholders. Defined by Moore, a business ecosystem can start from an existing collaboration and move towards growth and expansion, convergence, and finally business renewal [21]. From a knowledge management perspective, an innovation ecosystem consists of complex relationships between actors or entities whose functional objectives are to achieve technology development and creation [22]. Innovation ecosystems can evolve from randomly selected elements to structured communities [21]. Companies 
rely on cooperation and competition to produce products, meet customer needs, and ultimately develop their innovation capabilities [21]. Thus, this concept has extended traditional science and technology advancement towards a network of innovation. With stakeholder participation and the sharing economy, innovation is achieved beyond organizational boundaries. Collaboration and interaction between government, universities, and industry is considered to be crucial in promoting innovation and social development, and is known as the triple helix model [4]. With universities generating knowledge resources and industry providing profit through product development and commercialization, government can issue the rules of the game, facilitating knowledge creating and sharing [4]. The triple helix theory has been further developed to the quadruple helix model, with the inclusion of the new element of civil society, which is related to media, intermediary, culture, and society [23]. It is believed that the new model addresses cooperation and co-evolution in a dynamic process, through which new products, services, and solutions can be co-developed with users as leaders, designers, and creators [23]. This is consistent with Stilgoe et al.'s inclusion dimension of responsible innovation, where innovation involves a wider range of stakeholders, including society, in an open environment $[11,23]$.

In the context of the sharing economy and shared mobility, government policy can help to generate sustainability and responsible innovation. According to a report by the USA's Department of Transportation, there are emerging themes of the sharing economy's innovative mobility on demand [24]. In particular, business models and partnerships, land use and different urbanization scenarios, social equity and environmental justice, policies and standards, and enabling technologies have been identified as enablers of mobility in the demand ecosystem [24]. Among these, regional governments can issue policies including health, safety, and consumer protection; taxation, insurance, parking, and access to rights-of-way; equity and accessibility issues; full and fair participation; data sharing, privacy, and standardization; and livery laws to impact shared public transportation sectors [24]. Apart from this, as policies play an important role in transportation planning, public transportation, and parking policy, shared mobility can also be improved through signage and advertising, multimodal integration, and planning processes [25]. There are three models which local government can adopt to plan shared transportation [26]: (1) justifying the allocation of public resources and providing social and environmental support; (2) viewing shared mobility as sustainable business and providing moderate support; and (3) formalizing supply and demand management and pricing policies regarding shared mobility as business [26]. Shaheen et al. [27] has analyzed the evolution of the shared bicycle industry and has identified a fourth generation business model which features demand responsiveness and a multimodal system. It may be noted that safety, sustainability, and limited infrastructure remain as challenges for the shared bicycle industry [27]. In China, policies can already be found which support and standardize the shared bicycle sector as part of the fast-growing sharing economy. Since 2016, bicycle sharing has brought a series of problems to urban management in China. The traffic management departments of local governments and the Ministry of Transport of the Central Government have issued relevant policies to regulate management [28]. In December 2016, the Shenzhen Traffic Management Committee was the first in China to issue "Several Opinions on Encouraging and Regulating Internet Bicycles" [29]. It regulates the positioning of Internet bicycles and the responsibilities of government enterprises [28]. Since then, many local regulatory departments and trade associations in Beijing, Shanghai, Nanjing, and Guangzhou have introduced local regulations and regulations on shared bicycles [28]. For example, "The Draft of Shanghai's Shared Bicycle Solicitation" has clearly stipulated important social issues, including that sharing bicycles should be equipped with a GPS positioning system and that bicycle service life is obligated to last for three years [30]. At the level of central government, the Ministry of Transport also issued a macro-guidance policy on the development of shared bicycles in August 2017, namely, "Guidance on Encouraging and Regulating the Development of Internet Bicycle Rental", which clarifies the common problems of the shared bicycle industry [31]. The government's policies support the sharing of bicycles as an innovative means of Internet and traffic travel. Under the guidance of the macro-policy of the central government, 
in 2019, Jiangning District in Nanjing issued the "White Paper on Comprehensive Renovation of Non-Motorized Vehicles in Jiangning District of Nanjing", and established the first electronic fence monitoring system for shared bicycles in Jiangning District. The new forms of transportation are cross-border services and cross-border operations and the corresponding regulatory work also requires multi-sectoral cooperation [32]. In 2019, the Ministry of Transport together with the People's Bank of China introduced deposit management measures to further protect and manage users' deposits [33].

From the above literature review, it can be discerned that responsible innovation in the sharing economy is a new topic which requires exploration from different stakeholders and ecosystem perspectives. Currently, most research focuses on building conceptual frameworks and identifying key elements and dimensions, and there is lack of empirical studies. In addition, there has been limited research carried out to explore how responsible innovation can be achieved. Thus, this paper aims to provide details of elements related to responsible innovating from emerging sharing economies, and in particular from the perspective of China's shared bicycle sector. It will also explore the dynamic interactions between stakeholders, including industry, government, users, and universities, to form, develop, and maintain responsible innovation at the business ecosystem level.

\section{Research Methodology}

Given the nature of theory building and exploration, a qualitative method with case studies has been adopted for this research as it explores life-real activities and processes which are not known in detail [34]. Specifically, in-depth case studies have been conducted on the shared bicycle sector in China. This is a booming industry of the sharing economy but is now facing challenges. Data have been mainly collected from secondary documents, industry reports, and government policies, with a focus on the roles of and interactions between government, universities, industry, and society. Analysis focused on major phases of industry formation, expansion, convergence, and renewal. Key players and activities related to responsible and irresponsible innovation have been identified. Through content analysis and comparison, prioritized activities and values have been highlighted. While shared bicycle companies in China generally face challenges, the case of Hellobike provides details into how responsible innovation can be achieved along with value chain and business network management [35]. Thus, further linkages are able to be made between the existing literature and findings from this case study with regard to the dimensions of anticipation, reflexivity, inclusion, responsiveness, and co-evolution factors. The discussion also highlights the dynamic roles of government, industry, universities, and society in forming, developing, and sustaining new industries at different stages. Based on the research design and findings, further relevant themes are generated with the aim of theory testing and enrichment.

\section{Findings and Discussion}

\subsection{Industry Development and Challenges of Responsible Innovation}

\subsubsection{Stage One: Early Formation and Exploration (2014-2015)}

In 2014, four university graduates in Beijing jointly founded the shared bicycle company Ofo with the aim of facilitating short-distance trips inside university campuses. In May 2015, more than 2000 shared bicycles were used inside Beijing universities. Ofo then expanded to seven other cities, serving nearly 900,000 university teachers and students. Meanwhile, the first pile-less bicycles were introduced in Beijing. In 2016, another company, Mobike, came to the market in Shanghai, starting competition within the sector. With the aim of solving the last 1-3 kms of the daily commute, bicycle sharing quickly became popular in China [7].

\subsubsection{Stage Two: Expansion of the Industry (2016)}

To quickly occupy the market, Mobike and Ofo provided users with subsidies or free rides. They soon achieved advantages in first-tier cities in China. In 2016, Ofo launched 800,000 units of 
bicycles with a 51.2\% market share, while Mobike accounted for a $40.1 \%$ market share. Meanwhile as more companies joined, the industry witnessed diversity in terms of research and development (R\&D) and production, delivery, and promotion. The business model mainly relied on users' deposits to make a profit. By the end of 2016, more than 25 bicycle-sharing brands appeared, obtaining huge venture capital, and the total number of shared bike users in China reached 18.86 million [7].

\subsubsection{Stage Three: Convergence and Facing Challenges (2017)}

Without an overall plan and government control, shared bicycles increased to a significant scale and began to occupy public roads, causing problems for the transport system. In many cities, sidewalks were crowded with bicycles randomly parked. In Shanghai 2017, the number of shared bicycles was 1.78 million, i.e., three times over saturation. The local government had to stop new shared bicycle systems coming to market. In Shenzhen, there was a large disposal area of damaged shared bicycles, indicating irresponsible and improper usage from customers. This resulted in the decline of the shared bicycle industry in late 2017. In July 2017, users of Xiaoming Bicycle reported difficulties in getting deposits back, which triggered distrust between companies and customers. According to statistics, the suspension of industry operations led to an overall 1.5 billion RMB deposits being non-returned, damaging the rights of millions of consumers [8].

\subsubsection{Stage Four: Renewal and Awareness of Responsible Innovation (2018-Present)}

As it has been a bottom-up sharing economy sector, the Chinese government did not interfere in the shared bicycle industry in the early stages. In 2017, the Ministry of Transport and its relevant departments including the National Development and Reform Commission, the Ministry of Housing and Urban-Rural Construction, the People's Bank of China, and the China Banking Regulatory Commission conducted an in-depth investigation on the shared bicycle industry in Beijing, Guangzhou, Chengdu, and Changzhou, and formulated policies. Responsibility, consumer interest protection, promotion of user safety, and orderly development of the industry were emphasized [36]. In August 2017, the Ministry of Transport and ten other government departments jointly issued the Guidelines on Encouraging and Regulating the Development of Internet Bicycle Rental, encouraging bicycle companies to adopt 'deposit-free' schemes. This was followed by the Guidelines on Encouraging Standardized Development of Shared Bicycles in Beijing and the Guidelines on Encouraging and Regulating the Development of Internet-Leased Bicycles in Shanghai [36]. In November 2017, the China Communications Industry Association officially issued 'Overall Technical Requirements for Shared Bicycle Application System Based on Internet of Things'. This was formulated and issued by professional institutions such as the Internet of Things Application Branch of the China Communications Industry Association, Mobike, the China Information and Communication Research Institute. At the same time, the Chinese Consumer Association organized a dialogue between five leading shared bicycle companies to explore ways to protect consumers' rights and improve product safety. With policy support, industry standards, and user cooperation, shared bicycle business in China started to move towards responsible innovation [36].

\subsection{Case Analysis of Hellobike in Terms of Responsible Innovation}

Despite the failure of most shared bicycle companies in China, Hellobike, a company of the Hellotravel Group, has demonstrated good practice with regards to responsible innovation. Established in 2016, Hellobike survived the fierce competition of the rapid market expansion, technology advancement, and responsible innovation. Its activities can be analyzed in terms of product R\&D, operations, partnership, and engagement with users, government, and society (Figure 1). 


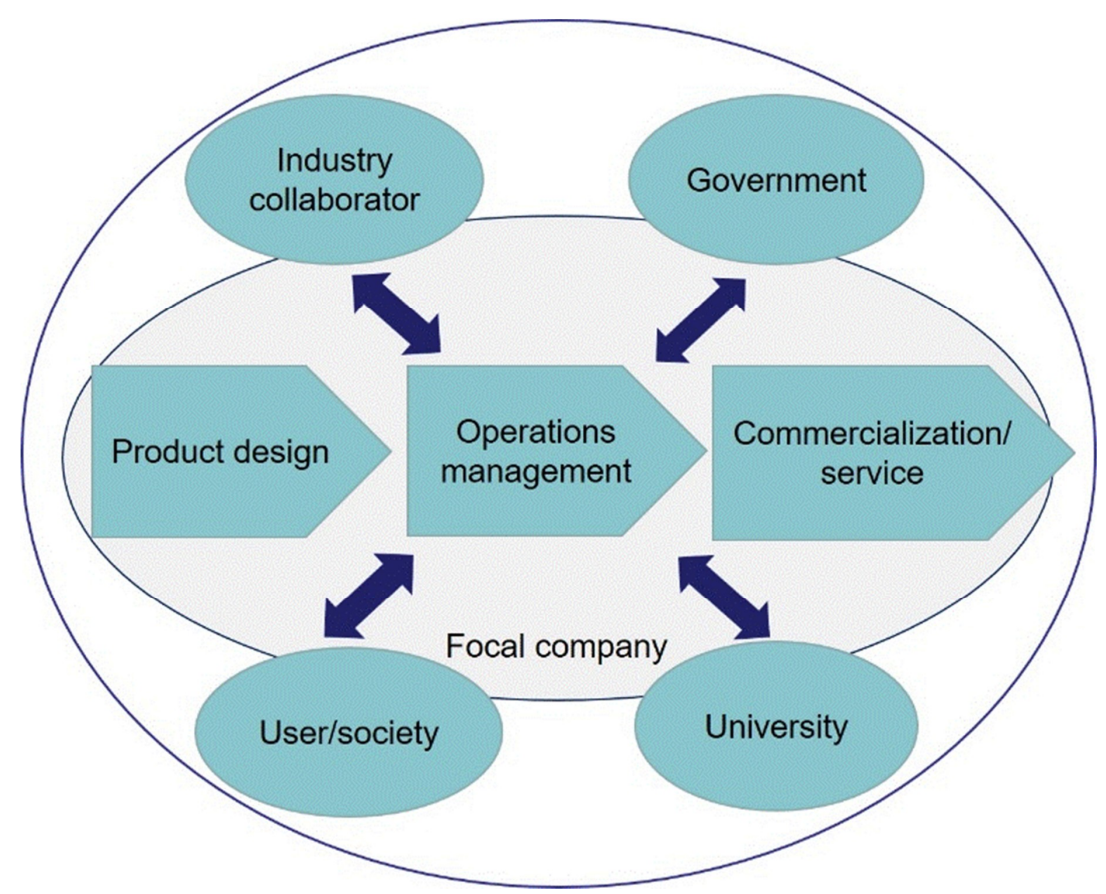

Figure 1. Responsible innovation of Hellobike within the value chain and business ecosystem.

\subsubsection{Product Design}

Hellobike 3.0 (a third-generation product) was launched in 2016. It reduces unnecessary assembly procedures and materials with a simplified design which can result in less maintenance costs and better user safety. For example, the body structure adopts an all-aluminum alloy frame which is $16 \%$ lighter than that of previous bikes. The ergonomically adjustable seat is equipped with a vacuum seat cushion which was jointly designed with sofa manufacturers and features flexibility, durability, and comfortableness (Hellobike, 2019). For accurate positioning consideration, Hellobike 3.0 uses GPS intelligent locks which can transmit real-time bike position and status. The R\&D team has tested the lock under severe high temperature ( 80 degrees Celsius), low temperature ( -40 degrees Celsius), and rainstorm conditions. The new locks nearly double the location accuracy and shorten the location time by $70 \%$, taking $10 \mathrm{~s}$ to unlock. Hellobike 3.0 also adopts a Bluetooth function to unlock as a backup to the Internet unlock function. An intelligent voice system is embedded to remind users of safety [35]. Using the Internet, Hellobike communicates with users to improve its product design [35].

\subsubsection{Operations Management}

For operations effectiveness and efficiency, Hellobike has established an intelligent big data platform called "Hubble System". This platform not only monitors bikes in real time, guiding the maintenance of off-line bikes, but also carries out data analysis of users' records and predicts citizen riding behavior. Within cities, the system can determine areas of hot spots and specific needs, so as to ensure that bicycles are not overloaded. When a bicycle breaks down, operators can react within $15 \mathrm{~min}$. Vital features such as the bicycle's power, operation, and maintenance are visible in background clouds [37]. AI technology can also identify whether users' breakdown reports are accurate or not. Judgement accuracy can reach $90 \%$, reducing unnecessary maintenance costs [35].

\subsubsection{Business Ecosystem Partners}

Since 2017, Hellobike has collaborated with partners across sectors. For example, it has worked with Fuxing Epinon Tourism Development Co., Ltd, a Shanghai based service company with the business of tourism planning and consulting, hotel management, and cultural and art exchange. To promote the theme of "Travel in the Most Natural Way". With the success of its new service, 
Hellobike planned a "3510" shared travel strategy including more projects for tourist spots, meaning shared bicycle services for short trips within $3 \mathrm{~km}$, shared electric bike services for trips covering 3 to $10 \mathrm{~km}$, and car sharing services to cover long trips of more than $10 \mathrm{~km}$ [38]. From an operations perspective, Hellobike worked with Weima Automobile in October 2017, using the Dongying city of Shandong Province as the first landing project. By integrating rental electric vehicles and shared bicycles, a brand-new " $4+2$ " (four-wheel plus two-wheel) service mode was launched to cover short $(0-5 \mathrm{~km})$ and long (more than $5 \mathrm{~km})$ journeys, promoting sustainable public transport [39]. Hellobike co-sponsored the "Future Development Trends of Shared Travel" forum in February 2018 and invited practitioners to exchange views on technology, knowledge, policy, and government support for the sharing economy. Scholars from the Institute of Transportation System Science and Engineering of Beijing Jiaotong University, the Center for Transportation Law and Development of Southeast University, the Academy of Transportation Science, and traffic police representatives attended the forum [40]. In December 2018, Hellotravel hosted an industry conference, inviting more than 100 suppliers and partners in the areas of communication technology, design, assembly and processing, and materials, including Tianjin Fujida, Luda Technologies, and China Mobile, to jointly explore opportunities and challenges of the shared bicycle sector which could contribute to standardization and institutions and upgrade the industry ecosystem [41].

\subsubsection{Users/Society}

To guide users' behavior, Hellobike's electronic fence technology was piloted in Jimei District, Xiamen city in March 2017. Combining an electronic parking system app, monitor, and GPS, the system can track bike positions, and then through the Internet of things technology coordinate bikes and parking spaces [37]. In March 2017, Hellobike launched a crowd voting event, promising deposit-free riding service if the votes reached 2 million [42]. In September 2017, Hellobike started a 365-day "Double Exemption" deposit exemption scheme for university students. According to the company, students have strong demand for short-distance travel and flexible travel time and are therefore long-term high-quality users [43]. Hellobike also offered free rides between $11 \mathrm{pm}$ and 6 am the next day, providing diversified travel options for citizens [44]. After deposit exemption, Hellobike implemented a user credit system. Users must park bicycles in the designated white line areas, bicycle rack locations, and roadside open areas without obstructing traffic. Each user has 100 credit points after registration, getting 1 point for each ride. Improper parking and damaging products will result in a 20-point deduction. When a user's credit score is below 80 , the price of riding is raised to $100 \mathrm{RMB} /$ half hour. After launching the credit system, more than 7000 users were punished by score deduction [37]. In addition, Hellobike initiated several voluntary activities in cooperation with not-for-profit organizations [45]. In December 2017, Hellobike signed an agreement with Shandong Province to manage shared bicycles from production to scrap to recycling, contributing to environmental sustainability [35].

\subsubsection{Government/Policy}

Hellobike actively cooperates with second- and third-tier city governments. Using its big data platform "Hubble System", it can schedule off-line bikes, predict riding behavior, and thus help to develop an intelligent transportation system [45]. The company works together with local governments in Nanchang, Luoyang, Zibo, and Quanzhou cities to promote green public travel plans [46]. To standardize the management of shared bicycles, including proper parking, a pilot project led by the Comprehensive Administrative Law Enforcement Bureau of the Xihu District of Hangzhou was held in July 2018, during which Hellobike tested its response to maintenance. This pilot event demonstrated a new model of in-depth collaboration between government, industry, and society [47]. 


\subsubsection{Universities}

Apart from inviting universities to industry forums, Hellobike's engagement with universities started in March 2019. Unlike Ofo, who started from university campuses and expanded to the mass market, Hellobike decided to move to university campuses when its business model had already matured in cities. Collaborating with Xiaoguo, a campus all-media platform, it developed customized bicycles with university logos which can be only used inside campuses, and established designated parking areas. Students were recruited as part-time coordinators to guide proper riding and parking. Using big data analysis, Hellobike is able to predict peak hours of university rides and respond to maintenance quickly, thus achieving sustainable development [48].

Figure 2 summarizes the stages of China's shared bike sector with highlights on industry, government policy, users, and universities as the main stakeholders.

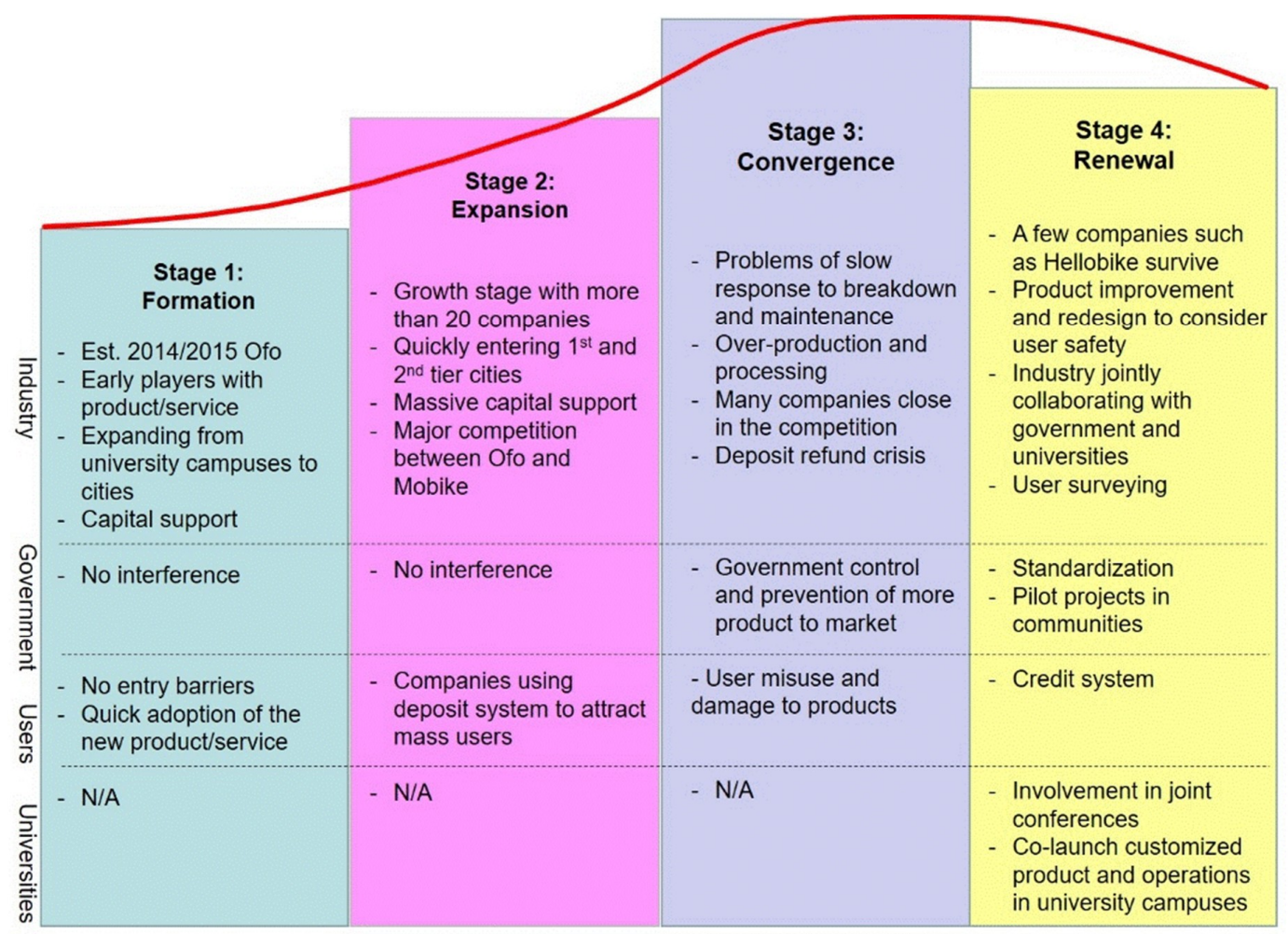

Figure 2. Life cycle of China's shared bicycle industry.

\subsection{Key Issues Resulting in Responsible and Irresponsible Innovation}

The chosen case study shows challenges and good practice. Through analysis, details of responsible and irresponsible activities in China's shared bicycle sector and Hellobike were identified, and have been coded and summarized in Table 1. The factors have been classified along the value chain from product design to operations and commercialization. The table also includes aspects of stakeholders in the business ecosystem, namely, business partners, universities, governments, and users, as a combination framework based on the ecosystem and quadruple helix model. There are certain factors in common which are important to both responsible and irresponsible innovation. These include having product safety embedded in design, real time monitoring and emergency responses, inter-industry collaboration, trusting systems between industry and users, and proper government policy and standardization. By prioritizing these factors, the shared bicycle industry can achieve responsible innovation, as in the case of Hellobike, whereas by ignoring them, business becomes irresponsible and unsustainable, as in the case of many other firms. 
Table 1. A comparison of Hellobike and other shared bicycle organizations in China.

\begin{tabular}{|c|c|c|}
\hline Activities & Hellobike (Responsible Factors) & Other Companies (Irresponsible Factors) \\
\hline Product design & $\begin{array}{l}\text { - Quality control and design friendliness } \\
\text { - Considering user convenience, comfortability, and safety } \\
\text { during research and development (R\&D) } \\
\text { - Reduce unnecessary material and assembly procedures } \\
\text { (ecological features) } \\
\text { - Continuous technology improvement/upgrades on } \\
\text { existing product design (GPS, locks) } \\
\text { - User communication to improve product design (via } \\
\text { internet) }\end{array}$ & $\begin{array}{l}\text { - Limited investment in product R\&D } \\
\text { - Limited quality control during production } \\
\text { - Product design not considering users' } \\
\text { requirements }\end{array}$ \\
\hline $\begin{array}{l}\text { Operations } \\
\text { management }\end{array}$ & $\begin{array}{l}\text { - Real time system monitoring } \\
\text { - Fast detecting and responding to failures } \\
\text { - Data analysis and AI technology to identify problems } \\
\text { - Data analysis to forecast demand }\end{array}$ & $\begin{array}{l}\text { - Over-production and -processing without } \\
\text { considering actual demand } \\
\text { - Industry lack of operations management } \\
\text { consciousness } \\
\text { - Failure to response to emergencies on time }\end{array}$ \\
\hline $\begin{array}{c}\text { Business ecosystem } \\
\text { partners }\end{array}$ & $\begin{array}{l}\text { - Cooperation and exchange among universities and } \\
\text { industries (conferences) } \\
\text { - Cooperation between upstream and downstream } \\
\text { industries } \\
\text { - Inter-industry cooperation to create business ecosystem }\end{array}$ & $\begin{array}{l}\text { - Malicious competition by companies to seize } \\
\text { market share of first-tier cities } \\
\text { - Lack of systematic cooperation between } \\
\text { upstream and downstream industries }\end{array}$ \\
\hline Users/society & $\begin{array}{l}\text { - Free deposit and free night travel for user convenience } \\
\text { - User needs surveying, crowd voting } \\
\text { - Credit system to promote civilized product usage and } \\
\text { standardization } \\
\text { - Free service to attract high-quality consumers such as } \\
\text { university students } \\
\text { - Philanthropic behavior such as voluntary events }\end{array}$ & $\begin{array}{l}\text { - Companies use deposits to assess mass market } \\
\text { without standards } \\
\text { - Users parking improperly } \\
\text { - Users damaging bicycles } \\
\text { - Users discarding broken bicycles }\end{array}$ \\
\hline Government/policy & $\begin{array}{l}\text { - Government promotes civilized cycling behavior } \\
\text { - Standardized management in pilot plots in cooperation } \\
\text { with local governments } \\
\text { - Policy support and guidance for industry standardization } \\
\text { - In-depth collaboration between industry and government } \\
\text { at community/district level }\end{array}$ & $\begin{array}{l}\text { - Lack of guidance and standardization } \\
\text { - Lack of market research } \\
\text { - No legal protection for consumers' rights } \\
\text { - Government fails to predict and manage traffic } \\
\text { chaos in time } \\
\text { - In the beginning, the government does not } \\
\text { interfere with industry but later adopts } \\
\text { restrictions rather than active guidance. }\end{array}$ \\
\hline Universities & $\begin{array}{l}\text { - Collaboration with industry to launch customized } \\
\text { products, services, and operation systems } \\
\text { - Attending industry forums }\end{array}$ & - Limited participation \\
\hline
\end{tabular}

\subsection{Dimensions of Responsible Innovation}

Existing literature has provided an important framework for responsible innovation along with the dimensions of anticipation, reflexivity, inclusion, and responsiveness [11]. In addition, the involvement of stakeholders, including universities, government, industry, and society can be found in triple helix [4] and quadruple helix models [23]. The dynamics of responsible innovation have also been highlighted in recent literature [18]. Thus, further analysis can be conducted from these dimensions and aspects, as shown in Table 2. While literature summarizes features of each dimension through content analysis and comparison with literature, the study of the shared bicycle sector can enrich the meaning of each dimension from practical perspectives, especially in the current era of Industrial 4.0 and the sharing economy. Findings highlight the co-evolution of stakeholders to form, develop, and sustain responsible innovation.

Table 2. Dimensions of responsible innovation.

\begin{tabular}{lll}
\hline \multirow{2}{*}{ Theories } & \multicolumn{1}{c}{ Literature and Theory } & \multicolumn{1}{c}{$\begin{array}{c}\text { Findings from China's Shared } \\
\text { Bicycle Industry }\end{array}$} \\
\hline & - Foresight & - R\&D improvement during early stages \\
& - Technology assessment & - Industry expansion (3510 project) \\
Anticipation [11] & - Horizon scanning & - Business model vision development \\
& - Scenarios & $(4+2$ model) \\
& - Vision assessment & - Pilot project before market expansion \\
& - Socio-literary techniques & \\
\hline
\end{tabular}


Table 2. Cont.

\begin{tabular}{|c|c|c|}
\hline Theories & Literature and Theory & $\begin{array}{l}\text { Findings from China's Shared } \\
\text { Bicycle Industry }\end{array}$ \\
\hline Reflexivity [11] & $\begin{array}{l}\text { - Multidisciplinary collaboration and training } \\
\text { - Embedded social scientists and ethicists in laboratories } \\
\text { - Ethical technology assessment } \\
\text { - Codes of conduct } \\
\text { - Moratorium }\end{array}$ & $\begin{array}{l}\text { - Feedback loop (e.g., customer surveying } \\
\text { and customers reporting product } \\
\text { breakdowns) } \\
\text { - Technology testing } \\
\text { - Quality improvement from } \\
\text { previous designs } \\
\text { - Customization }\end{array}$ \\
\hline Inclusion [11] & $\begin{array}{l}\text { - Consensus conferences } \\
\text { - Citizens' juries and panels } \\
\text { - Focus groups } \\
\text { - Science shops } \\
\text { - Deliberative mapping } \\
\text { - Deliberative polling } \\
\text { - Lay membership of expert bodies } \\
\text { - User-centered design } \\
\text { - Open innovation }\end{array}$ & $\begin{array}{l}\text { - Cross-organizational collaboration } \\
\text { - Cross-industry (supply chain and } \\
\text { ecosystem) collaboration } \\
\text { - Collaboration with local government } \\
\text { - Industry-university joint conferences }\end{array}$ \\
\hline Responsiveness [11] & $\begin{array}{l}\text { - Constitution of grand challenges and thematic research } \\
\text { programs } \\
\text { - Regulations } \\
\text { - Standards } \\
\text { - Open access and other mechanisms of transparency } \\
\text { - Niche management } \\
\text { - Value-sensitive design } \\
\text { - Moratoriums } \\
\text { - Stage-gates } \\
\text { - Alternative intellectual property regimes }\end{array}$ & $\begin{array}{l}\text { - Internet of Things systems for monitoring } \\
\text { - Information sharing of user credit } \\
\text { - Government guidance on proper usage of } \\
\text { the product } \\
\text { - Legal framework improvement } \\
\text { - Electric fence technology to guide } \\
\text { proper usage } \\
\text { - Pilot studies in certain communities and } \\
\text { districts, then expanding towards the } \\
\text { whole city }\end{array}$ \\
\hline $\begin{array}{c}\text { Other factors, e.g., } \\
\text { co-evolution/dynamics } \\
{[4,18,23]}\end{array}$ & $\begin{array}{l}\text { - Triple helix (interactions between universities, industry, } \\
\text { and government) } \\
\text { - Quadruple helix (interactions between universities, } \\
\text { industry, government, and civil society } \\
\text { - Business ecosystems } \\
\text { - Innovation ecosystems }\end{array}$ & $\begin{array}{l}\text { - Trust and commitment between industry } \\
\text { and customers } \\
\text { - User awareness of responsibility } \\
\text { - Philanthropic behavior } \\
\text { - Industry collaboration } \\
\text { - Industry-government-society collaboration } \\
\text { - Upgrading from supply chain } \\
\text { towards ecosystems } \\
\text { - Reshaping the industry } \\
\text { towards responsibility }\end{array}$ \\
\hline
\end{tabular}

\subsection{Interactions between Industry, Government, Users, and Universities}

Following China's shared bike industry lifecycle (Figure 2), it can be seen that dynamics, co-evolution, and interactions between stakeholders are the main features. Though many firms fail to reach sustainable and responsible business models, the case study of Hellobike in particular reveals that industry, government, users, and universities should work together to form a responsible innovation ecosystem. Thus, further process mapping focusing on the role of government, industry, users, and universities at different stages, namely, the formation, expansion, maturity, and renewal of responsible innovative ecosystems can be conducted, highlighting dynamic changes. This can extend the current literature on responsible innovation, where government policy is the main driving force, and link the business ecosystem, triple helix, and quadruple helix models.

First, in the early formation stage of China's shared bike industry, companies initiated technology and business model innovation without government participation. However, this caused many problems due to lack of standardization and an overall plan. From Hellobike's practice, it can be seen that companies can work together with local government to promote brand image and to test the operations system on a small scale such as within a community or district, after which expansion towards the whole city can occur. Thus, co-operation between industry and government can avoid risks in the early stages of the industry life cycle. Meanwhile, industry needs to explore users' needs and consider user safety and friendliness during the product design stages. During this stage, industry plays a leading initiating role and directs support from government and customers. The relationship shows a predominantly one-way direction from industry to government and customers. There is limited interaction and participation from universities. 
Second, with increasing competitor participation, the shared bicycle industry in China experienced diversity, flexibility, and customer engagement. However, due to a lack of control, corporate social responsibility (CSR), and sustainability, related risks emerged. Due to lack of regulation frameworks and standardization, competition was unhealthy. Thus, it is essential for government to take a leading role and provide standardization for industry in its growth stage. Meanwhile, government and industry can collaborate together to guide proper and responsible consumer behavior.

Thirdly, when the shared bike industry in China became mature, companies without compliance with legal responsibilities exited the business and the industry converged towards a limited number of players with continuous improvement and active communication with the public. As seen in the case of Hellobike, it continued to improve its technology, design, and maintenance systems. In addition, it further considered the relationship between industry and users, launching a series of promotional events. Through collaboration, it introduced a credit system, improving user awareness of responsibility in a tangible way. At this stage, government can work together with industry to plan and monitor transportation, as in the case of Hellobike. There is an in-depth partnership between government, industry, and users. Thus, joint efforts should be made among stakeholders to sustain the industry.

Finally, the renewal stage of the shared bike sector in China occurs. Technology improvement, which can be achieved through university and industry collaboration, becomes important. In the case of China's shared bicycle industry, there is already a trend for joint forums where industry and universities discuss the future trends of shared bicycles. Industry and universities can collaborate on customized products and operations inside university campuses. While government provides a platform to bridge more research projects, the system can achieve self-organization without supervision. This demonstrates a potential sustainable model with a balance of stakeholders to improve service quality.

To summarize, Figure 3 demonstrates the evolution of the relationship between different players in the shared bicycle industry, which can lead to responsible innovation.

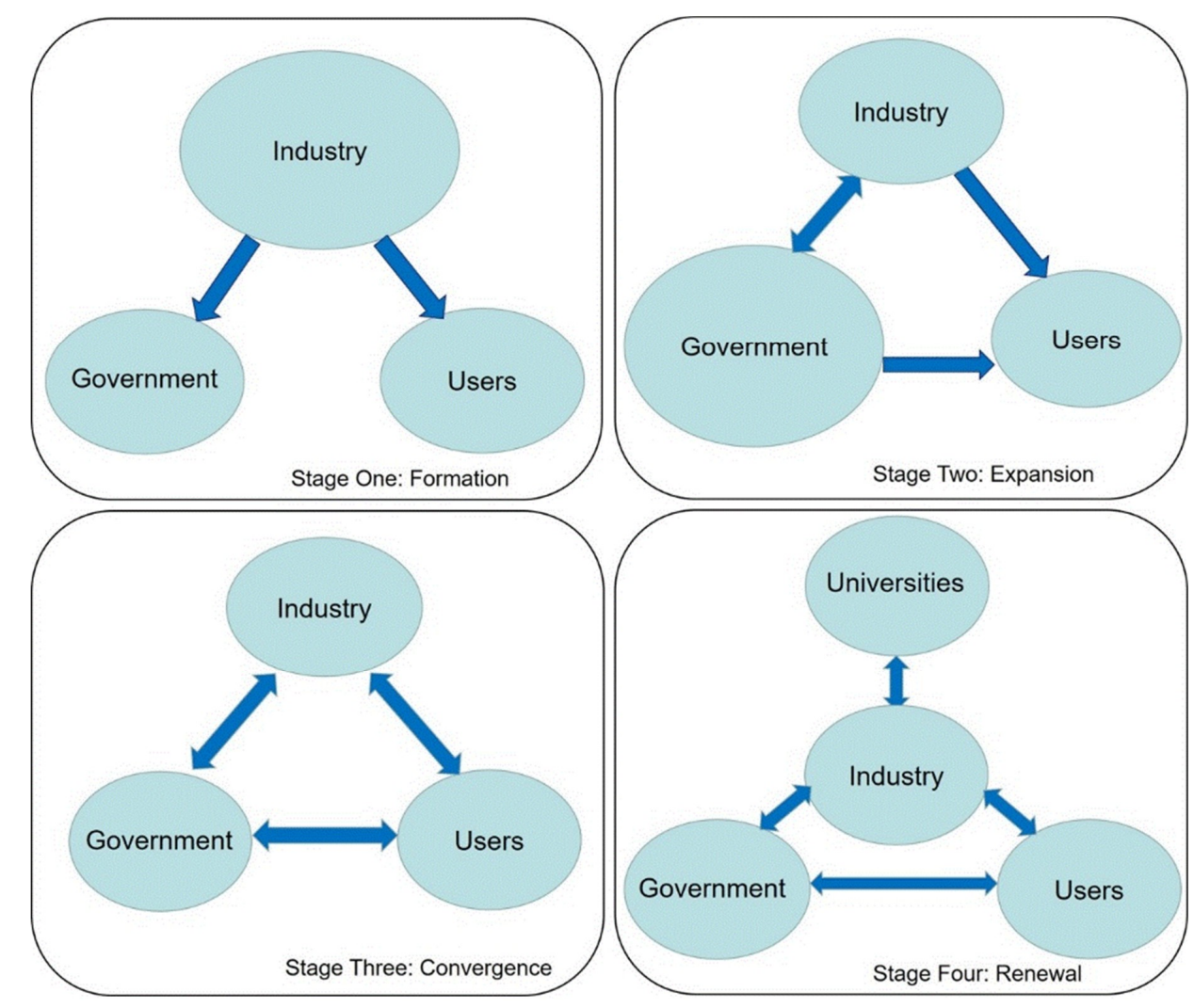

Figure 3. Industry-government-user-government interactions in a responsible innovation ecosystem. 


\section{Conclusions}

In the era of big data, $\mathrm{AI}$, and the sharing economy, innovation is increasingly conducted with the participation of stakeholders, including industry, government, universities, and users, who are present in the triple helix and quadruple helix models. Industry and universities remain sources of knowledge, while government can promote frameworks and standards. Through crowd sourcing, voting, and funding, users are no longer passive buyers but active co-creators of new products and services. Thus, the current innovation ecosystem of which this is an example is more complex and dynamic, interacting with the environment and society. Responsible innovation explores how innovation can be conducted in a transparent, caring, and orderly way, so as to contribute to safety, sustainability and wellbeing. The concept goes beyond CSR, expanding from the company level towards collaboration among stakeholders in a business ecosystem. As a new theory, most research aims to build conceptual frameworks with limited empirical studies, especially from emerging country perspectives.

This paper has aimed to explore factors of responsible innovation, linking dimensions with industry practice, and identify the dynamic stages of the industry lifecycle. Through an in-depth study of China's shared bicycle industry and the case company of Hellobike, prioritized elements have been pointed out which include considering user safety and friendliness during product design, real-time operations combined with big data technology, collaboration among industry and local government for industry standardization, and user credit systems. In the early stages, industry plays a leading role and government can participate to issue supporting frameworks. Government can also bridge industry and users to promote trusting relationships later on. When the responsible innovation system becomes mature, more actors, such as universities, can participate, allowing the self-management and industry renewal stages to be reached.

While current literature focuses on elements of responsibility separately, this paper has viewed responsible innovation from holistic stakeholder perspectives. It has enriched the different dimensions by interpreting them in the context of the sharing economy. Furthermore, the study has identified the dynamic interactions between and changing roles of industry, government, universities, and society at different stages of the innovation ecosystem. Although our study has focused on China's shared bike sector with a specific case study, its findings can be applied to other sharing economy sectors including general sharing transportation. As the sharing economy is driven through demand and supply sharing, a co-creative of value can be achieved through shareholder interaction, leading to the forming, developing, and sustaining of innovation in a responsive way. Anticipating future needs can help to develop resources and capability while reducing unnecessary waste. Reflexivity requires co-design with users concerning product and service safety. Inclusion innovation becomes important with regard to engaging with society, sometimes generating social values. Responsiveness also needs a co-evolution approach to solve problems and reduce risk. Practitioners from the sharing economy can gain knowledge to understand innovation and its impact on the environment and society, prioritizing elements related to responsible innovation. Deeper capturing of responsible innovation characteristics will also help policy makers to develop insights into industry trends and interaction mechanisms, changing regulations according to different stages of the innovation ecosystem.

Limitations do exist in this study as a single sector cannot represent the whole sharing economy and data have been mainly collected from secondary sources. More case studies may be conducted with primary sources to enrich findings and validate the dynamic model. With our analysis in mind, future research may focus on the changing role of government policy in responsible innovation at different stages and the trusting relationship between industry and the public.

Author Contributions: Conceptualization, Z.L., L.M., Y.Z., and W.J.; methodology, Z.L. and L.M.; formal analysis, Z.L., L.M., and W.J.; investigation, Z.L., L.M., Y.Z., and W.J.; resources, Z.L., L.M., W.J., and Y.Z.; writing-original draft preparation, Z.L.; writing-review and editing, Z.L., L.M., Y.Z., and W.J.

Funding: This research was funded by the National Natural Science Foundation of China (NSFC), P.R. China (no. 71272164); the Fund of Research for Decision Making and Consultation of Jiangsu Service-Oriented Government Construction, China; and the Faculty of Business and Society Dean's Research Fund, University of South Wales, U.K. 
Conflicts of Interest: The authors declare no conflict of interest.

\section{References}

1. Gupta, A.K.; Dey, A.R.; Shinde, C.; Mahanta, H.; Patel, C.; Patel, R.; Sahay, N.; Sahu, B.; Vivekanandan, P.; Verma, S.; et al. Theory of open inclusive innovation for reciprocal, responsive and respectful outcomes: Coping creatively with climatic and institutional risks. J. Open Innov. Technol. Mark. Complex. 2016, 2, 16. [CrossRef]

2. Gupta, A.; Dey, A.; Singh, G. Connecting corporations and communities: Towards a theory of social inclusive open innovation. J. Open Innov. Technol. Mark. Complex. 2017, 3, 17. [CrossRef]

3. Yun, J.J. How do we conquer the growth limits of capitalism? Schumpeterian Dynamics of Open Innovation. J. Open Innov. Technol. Mark. Complex. 2015, 1, 2. [CrossRef]

4. Etzkowitz, H.; Leydesdorff, L. The dynamics of innovation: From National Systems and "Mode 2" to a Triple Helix of university-industry-government relations. Res. Policy 2000, 29, 109-123. [CrossRef]

5. Sharing Economy. Available online: https://www.investopedia.com/terms/s/sharing-economy.asp (accessed on 15 May 2019).

6. Airbnb. Your safety is our priority. Available online: https://www.airbnb.com/trust (accessed on 15 May 2019).

7. State Information Center. China Sharing Economy Development Annual Report. Available online: http: //www.yixieshi.com/82406.html (accessed on 15 May 2019).

8. State Information Center. China Sharing Economy Development Annual Report. Available online: http: //www.199it.com/archives/841592.html (accessed on 15 May 2019).

9. European Commission. Responsible Research \& Innovation. Available online: https://ec.europa.eu/ programmes/horizon2020/en/h2020-section/responsible-research-innovation (accessed on 15 May 2019).

10. Von Schomberg, R. Prospects for technology assessment in a framework of responsible research and innovation. In Technikfolgen Abschätzen Lehren: Bildungspotenziale Transdisziplinärer; Dusseldorp, M., Beecroft, R., Eds.; Vs Verlag, Methoden: Wiesbaden, Germany, 2011.

11. Stilgoe, J.; Owen, R.; Macnaghten, P. Developing a framework of responsible innovation. Res. Policy 2013, 42, 1568-1580. [CrossRef]

12. Davis, M.; Laas, K. Broader impacts or responsible research and innovation? A comparison of two criteria for funding research in science and engineering. Sci. Eng. Ethics 2014, 4, 963-983. [CrossRef] [PubMed]

13. Li, F.; Owen, R.; Simakova, E. Framing responsible innovation in synthetic biology: The need for a critical discourse analysis approach. J. Responsible Innov. 2015, 2, 104-108. [CrossRef]

14. Stahl, B.C. Responsible research and innovation: The role of privacy in an emerging framework. Sci. Public Policy 2013, 40, 708-716. [CrossRef]

15. Douglas, H.E. The moral responsibilities of scientists (tensions between autonomy and responsibility). Am. Philos. Q. 2003, 40, 59-68.

16. Liu, Z. Literature review of responsible innovation: Background, current situation and future trend. Sci. Technol. Prog. Policy 2015, 11, 155-160.

17. Liu, Z. Responsibility finitude and its enlightenment for responsible innovation. Stud. Dialectics Nat. 2015, $10,41-45$.

18. Mei, L.; Chen, J. The transfer of innovation paradigm: Rise of research on responsibility innovation. Sci. Manag. 2014, 3, 3-11.

19. Xue, G.; Zhao, Y. Transformation of EU S \& T policy based on RRI and its references to China. Forum Sci. Technol. China 2017, 4, 172-177.

20. Ma, L. Decode the Black Box of Continuous Innovation on Organizational Habitual Domains; Intellectual Property Publishing House: Beijing, China, 2017.

21. Moore, J.F. Predators and prey: A new ecology of competition. Harv. Bus. Rev. 1993, 71, 75-86. [PubMed]

22. Jackson, D.J. What Is an Innovation Ecosystem; National Science Foundation: Arlington, VA, USA, 2011. Available online: http://erc-assoc.org/sites/default/files/topics/policy_studies/DJackson_Innovation\% 20Ecosystem_03-15-11.pdf (accessed on 15 May 2019).

23. Carayannis., E.G.; Campbell, D.F.J. "Mode 3" and "Quadruple Helix": Toward a 21st century fractal innovation ecosystem. Int. J. Technol. Manag. 2009, 46, 201-234. [CrossRef] 
24. Shaheen, S.; Cohen, A.; Yelchuru, B.; Sarkhili, S. Mobility on Demand: Operational Concept Report; Department of Transportation: Washington, DC, USA, 2017; pp. 17-153. Available online: https://rosap.ntl.bts.gov/view/ dot/34258 (accessed on 30 June 2019).

25. Shaheen, S.; Cohen, A.; Zohdy, I. Shared Mobility: Current Practices and Guiding Principles. Available online: https://ops.fhwa.dot.gov/publications/fhwahop16022/fhwahop16022.pdf (accessed on 30 June 2019).

26. Cohen, A.; Shaheen, S. Planning for Shared Mobility. Available online: https://www.planning.org/ publications/report/9107556 (accessed on 30 June 2019).

27. Shaheen, S.; Guzman, S.; Zhang, H. Bikesharing in Europe, the Americas, and Asia: Past, present, and future. Transp. Res. Rec. 2011, 2143, 159-167. [CrossRef]

28. Meng, F. Quantitative analysis based on policy: Exploration of China's shared bicycle policy and related suggestions. J. Taiyuan City Vocat. Tech. Coll. 2018, 4, 164-167.

29. Shenzhen Transportation Commission. Announcement on Public Solicitation for Relevant Opinions on Encouraging Standardization of Internet Bicycles. Available online: http://www.sz.gov.cn/cn/xxgk/zfxxgj/ tzgg/201612/t20161227_5773534.htm (accessed on 30 June 2019).

30. Shanghai Government. Circular of the Shanghai Municipal People's Government on the Issuance of the Guiding Opinions on Encouraging and Regulating the Development of Internet-Leased Bicycles in Shanghai. Available online: http://www.shanghai.gov.cn/nw2/nw2314/nw2319/nw12344/u26aw54099.html (accessed on 30 June 2019).

31. Ministry of Transport of the People's Republic and China. The Ministry of Transport and Other Ten Departments Jointly Promulgated Guidelines for Sharing Bicycle Development and Implemented Policies to Encourage Development and Standardize Operation and Service Behavior. Available online: http://www. mot.gov.cn/zxft2017/yss_0803/xiangguanziliao/201708/t20170803_2803520.html (accessed on 30 June 2019).

32. Jiangsu Pioneered the Electronic Fence Monitoring System, Specializing in the Random Parking of Shared Bicycles. Available online: http://www.jsti.com/index.php/show/index/995 (accessed on 30 June 2019).

33. Ministry of Transport of the People's Republic and China. Circular of the Ministry Of Transport, The People's Bank of China, The State Development and Reform Commission, The Ministry of Public Security and The Banking and Insurance Regulatory Commission of The General Administration of Market Supervision on The Issue of Measures for The Management of Users' Funds in New Traffic Forms. Available online: http://xxgk.mot.gov.cn/jigou/ysfws/201905/t20190515_3201064.html (accessed on 30 June 2019).

34. Yin, R.K. Case Study Research: Design and Methods; Sage: Thousand OK, USA, 2003.

35. Hellobike. Available online: https://www.hellobike.com/ (accessed on 15 May 2019).

36. SQXFW.Net. Sharing Bicycles Coming into the "Deposit Free Ride", Hellobike Started Credit System to Replace Deposit in 10 Cities; SQXFW.Net: Xi'an, China, 2017; Available online: http://www.sqxfw.net/n/20171128/1581.html (accessed on 15 May 2019).

37. Hellobike Winning the Best Growing Company of the Year in the Winter Forum of China Finance and Economics Summit. CB.COM.CN: Beijing, China, 2017. Available online: http://www.cb.com.cn/gdbb/2017_ 1201/1212939.html (accessed on 15 May 2019).

38. Hellobike and Fosun Albion Strategic Cooperation for Scenic Intelligent Shared Travel. Available online: http://news.cncn.net/c_748065 (accessed on 15 May 2019).

39. Weima Motor Releases Smart Travel Brand by $4+2$ Collaboration with Hellobike. Available online: http://www.chinanews.com/auto/2017/09-26/8340546.shtml (accessed on 15 May 2019).

40. The Winter Forum of China Traffic Channel Was Held, Hellobike Wining “Best Traffic Safety Company' Award. Available online: http://www.ctoutiao.com/497526.html (accessed on 15 May 2019).

41. Hellobike Held the First Industry Conference for Industrial Chain Sustainability. Available online: http: //www.changjiangtimes.com/2018/12/591445.html (accessed on 15 May 2019).

42. Hellobike Took the Lead in Launching Deposit-Free Cycling, Reaching 160 Million Users. Available online: http://finance.eastmoney.com/news/1365,20180313842893342.html (accessed on 15 May 2019).

43. Hellobike's Welfare: 365 Day Free Ride with No Deposit for University Students Nationwide. Available online: http://hn.qq.com/a/20171009/034788.htm?pc (accessed on 15 May 2019).

44. Hellobike Announced Free Night-Time Cycling. Available online: http://www.enet.com.cn/article/2016/1108/ A20161108022255.html (accessed on 15 May 2019). 
45. One Year Anniversary, from 0 to 30 Million, Hellobike Continues to be in the Top Three of the Industry. Available online: http://finance.youth.cn/finance_cyxfgsxw/201709/t20170920_10752417.htm (accessed on 15 May 2019).

46. NEWS.IFENG.COM. Hellobike won the "China Public Welfare Festival 2017 Internet Corporate Social Responsibility Award". Available online: http://news.ifeng.com/a/20180130/55615605_0.shtml (accessed on 15 May 2019).

47. Xihu District Comprehensive Administrative Law Enforcement Bureau Worked Together with Hellobike for the First Pilot of Civilized Cycling in China. Available online: http://tech.chinadaily.com.cn/2018-07/04/ content_36511293.htm (accessed on 15 May 2019).

48. Xiaoguo Institute. Hello Bicycle Opened up a New Bicycle Market for Universities. Available online: https://www.xiaoguokeji.com/news/562 (accessed on 15 May 2019).

(C) 2019 by the authors. Licensee MDPI, Basel, Switzerland. This article is an open access article distributed under the terms and conditions of the Creative Commons Attribution (CC BY) license (http://creativecommons.org/licenses/by/4.0/). 